\title{
O "Centro Del bambini e delle famiglie": uma nova possibilidade para 0 atendimento de crianças ${ }^{1}$
}

\author{
Celia Vectore ${ }^{2}$ \\ Universidade Federal de Uberlândia
}

\begin{abstract}
Resumo
Este trabalho apresenta e analisa, em termos das possibilidades de implantação e primeiras avaliações, a experiência italiana relativa aos cuidados com a criança, representada pelos atuais "Centros das Crianças e das Famílias". Trata-se de um novo serviço de natureza sócio-educativa que tem como objetivo oferecer instrumentos de apoio à difícil tarefa dos genitores bem como proporcionar oportunidades adequadas de desenvolvimento tanto para as crianças quanto para suas famílias. O artigo lança algumas luzes para a utilização do referido serviço em contexto brasileiro.
\end{abstract}

Palavras-chave: criança; família; serviço.

\section{The "Centro Del bambini e delle famiglie": a new possibility for the attendance of children}

\section{Summary}

This job presents and analyses, in terms ofthe possibilities of implantation and evaluations, the Italian experience related to children care, represented by the existing "Centri Del bambini e delle famiglie". 1t is a question of a new service with a social-educative nature that has the objetive of providing support instruments to developing opportunities, both for children and to their families. The article points out some light to the use of the referred service in a Brazilian context.

Key-Words: child; family, service.

Em nenhum momento da história da educação e dos cuidados prestados ao ser humano em desenvolvimento, o pré-escolar foi objeto de tamanha atenção, em escala internacional, como vem sendo presentemente. Após um passado relativamente próximo de poucas tentativas isoladas e relativo desinteresse dos pesquisadores mais qualificados, a educação pré-escolar ganhou extraordinária relevância, tanto no exterior como em alguns círculos específicos do país, conforme se comprova pela extensa literatura hoje em dia disponível a esse respeito.

Vários fatores contribuíram para faZer com que os seis primeiros anos de vida passassem a contar com um realce, nos âmbitos educacional e psicológico, que não tiveram no passado. Sem o propósito de analisar em profundidade essa pluralidade de possíveis fatores e condições, poder-se-á, no entanto, lembrar alguns deles, mais óbvios:

- preocupação com a redução de desigualdades sociais e com as causas e conseqüências da pobreza, mobilização precoce de recursos que reduzam ou neutralizem a possibilidade de malogro na escola, em nível de primeiro grau;

- agravamento de problemas ligados à vida em cidades, em virtude dos processos, em expansão acelerada, de urbanização, industrialização e competição social;

\footnotetext{
1 Experiência observada durante o período de pós-doutorado realizado em Ferrara. Itália. em 1995-1996.

2 Doutora em Psicologia Escolar - Departamento de Psicologia Social e Educacional.
} 
- surgimento de uma nova organização social, em função de mudanças na concepção da família tradicional, ou seja, aumento da instabilidade matrimonial, aumento de família com apenas um genitor (só o pai ou só a mãe), crescimento de família com apenas um filho, fatores que podem ter contribuído, segundo Catarsi (1993), na origem do fenômeno da "solidão" infantil, pois não raro, as crianças são privadas de experiências sociais, em virtude de suas vidas estarem condicionadas ao escasso tempo do mundo adulto;

- crescimento, ano após ano, da percentagem da força de trabalho feminina, particularmente no que respeita às mulheres jovens, mães de filhos pequenos;

- maior e melhor reconhecimento da importância decisiva dos primeiros anos de vida no desenvolvimento de uma personalidade sadia e na prevenção de distÚrbios mentais;

- melhor conhecimento das variáveis e condições de natureza genética, nutricional, higiênica, psicológica, social e ambiental que influem de modo substantivo no desenvolvimento da criança pequena e podem produzir danos irreparáveis nesse desenvolvimento nos anos subseqüentes.

Contudo a plena compreensão da importância dos seis primeiros anos de infância e dos principais aspectos do desenvolvimento físico, mental e social nessa idade surgiu em época relativamente recente - em fins do século passado - estando longe de ter sido encerrada a história das pesquisas sobre o que acontece de significativo na vida e na personalidade da criança antes dos sete anos (cf. Gordon, 1972; Evans, 1975; Almy, 1977; Klein, 1996).

Cresceu, assim, na maioria dos países, substancialmente, a consciência da relevância de cuidados educacionais e bem-estar da criança, antes dos sete anos, redundando em recomendações de iniciativas, projetos e procedimentos nesta área, assim como a multiplicação da literatura, materiais didáticos, preocupações com o preparo mais adequado, o aperfeiçoamento dos docentes, a assistência permanente a estes, uma contínua busca de melhoria de qualidade e de generalização dos serviços pré-escolares.

Convém lembrar que o caráter dicotômico dos serviços para a infância, ou seja, educativo ou assistencial deve ser ponto para reflexões, pois tais aspectos parecem interagir e necessitam ser superados, a fim de que' não impeçam o desenvolvimento de novas alternativas de trabalho.

Assim, o objetivo do presente trabalho é contribuir no sentido de apresentar novas propostas de atendimento à infância, principalmente as que buscam, através de um serviço sócioeducativo, a recuperação da importância dos primeiros anos de vida na formação das pessoas - necessidade de se ter um homem mais solidário, propiciando o seu crescimento e o seu desenvolvimento, por meio de uma multiplicidade de experiências e mediante o confronto e a troca com mais interlocutores sociais: a família, a escola e o grupo de pares.

Dentro desse contexto, é interessante apontar a experiência italiana relativa aos cuidados com a criança, representada pelos atuais "Centros das Crianças e das Famílias", cujo objetivo precípuo é propiciar oportunidades de vida e de relação sócio-educativa para as crianças e suas famílias, além de fornecer instrumentos válidos de apoio à difícil tarefa dos genitores. Trata-se de um serviço integrado com os asilos "nidi" ${ }^{2}$ (criança de 0 a 3 anos), alternativo à pré-escola tradicional e também à televisão, pois é cada vez maior o número de horas que a criança italiana pennanece frente à T.V.(Musatti, 1992).

\footnotetext{
2 Para melhor compreensão, os asilos "nidi" (em português, ninhos) podem ser entendidos como creches.
} 
Segundo Barbini (1993), o serviço deve ser um "laboratório" cultural a favor da infância, enfatizando a observação das crianças e adequando os profissionais e suas atividades às necessidades infantis, num contínuo processo de troca. A criança está no centro desse processo, não como "projeto de homem", mas como uma pessoa plena de direitos, que constrói a própria identidade numa relação contínua e integrada com a comunidade de pares, com os adultos, com a sociedade e com a natureza. Assim, a família é um ponto essencial do projeto educativo construído dialeticamente a partir das necessidades da criança.

\section{Considerações sobre os "centri Del bambini e delle famiglie"}

Os últimos vinte anos foram marcados por profundas transformações em escala mundial, de natureza sócio-econômica e cultural. O desenvolvimento tecnológico, a inserção da mulher no mercado de trabalho, as mudanças ocorridas no núcleo familiar - divórcio, famílias com apenas um dos genitores etc., foram alguns dos fatores que deram origem a uma nova organização da vida social, conforme mencionado anteriormente.

Mergulhados dentro desta nova ordem social e sofrendo as conseqüências das constantes ausências maternas, freqüentem ente em virtude do trabalho fora do lar, estão as crianças, cujo conceito de infância foi mudado no curso dos últimos séculos, passando-se do descaso observado no passado ao indubitável reconhecimento social e cultural dos dias de hoje.

A Itália, país onde os centros estão sendo amplamente implementados, vem, desde os anos setenta, propondo alternativas para atender as necessidades de suas crianças, bem como as de suas famílias. Assim, a lei 1.044 de 1971 estabeleceu os asilos "nidi" (ninhos) para crianças de zero a três anos, priorizando as necessidades dos genitores que, absorvidos pelo trabalho, não podiam cuidar diretamente dos filhos, tendo, dessa forma, a função precípua de custódia.

No início dos anos oitenta, os "nidi" passaram a ser procurados por outros tipos de famílias, desejosos de seus serviços, onde não necessariamente a mãe trabalhava fora. Além disso, a necessidade do serviço esbarrou com o aumento de déficit público, agravado em virtude da diminuição do crescimento do produto interno, do declínio da natalidade e da ampliação da expectativa de vida da população, como é o caso de Ferrara, cuja estimativa é de que, nos próximos anos, para cada indivíduo com menos de dezoito anos, ter-se-ão sete indivíduos com mais de 65 anos, confonne explica Barbini (op. cit.). Assim, as creches para crianças de 0-3 anos foram continuamente modificadas, a fim de atender aos novos tipos de demanda. Ressalta-se que tais modificações ocorreram e vêm ocorrendo através de uma prática reflexiva sobre a "programaçãoprojeto" educativo, da documentação da experiência, da oportunidade de remodelamento contínuo do projeto, da atualização (reciclagem) do pessoal, da construção da memória da experiência das crianças e também da coordenação psicopedagógica (Catarsi, 1988; Catarsi e Fortunati, 1989).

Vale lembrar que, atualmente, a oferta de serviço nessas instituições é pouca frente à demanda e novas alternativas estão sendo continuamente buscadas e testadas para a agilização dos referidos serviços, enquadrando-se, nesse caso, o centro para crianças e suas famílias. Ghedini (1993) apresenta uma estatística preocupante, pois apenas $5 \%$ das crianças italianas nesta faixa etária são atendidas pelas creches e, de uma forma heterogênea, pois concentram-se principalmente ao norte do país e são praticamente inexistentes no sul da Itália.

É importante considerar que o projeto sócio-educativo para crianças e famílias apóia-se em teorias e pressupostos que consideram a importância de um adequado desenvolvimento global na 
infância. Assim, é possível identificar nas diretrizes dos trabalhos, contribuições oriundas da ótica construtivista (Camaioni, 1980; Emiliani e Carugati, 1985; Schaffer, 1984 e 1990), como também ênfases na maturação da inteligência e na construção do real (Fomasa e Barbetta, 1988; Fomasa, 1989; Fomasa, Del Campo e Vanni, 1991), além da consideração aos aspectos do desenvolvimento afetivo, apontados pela teoria psicanalítica (Stem, 1987; Becchi e Bondioli, 1988; Bondioli, 1988, 1989, 1990). Dessa maneira, busca-se uma adequada articulação dos conhecimentos advindos da ciência psicológica na orientação das práticas educativas vivenciadas no trabalho do dia-a-dia nessas instituições.

Dentro desse contexto, alguns princípios básicos que norteiam o trabalho nos centros para crianças e suas famílias são frutos de recentes contribuições científicas que consideram a capacidade precoce da criança para se adaptar. Sendo assim, é interessante que tenha e forme relações satisfatórias com a mãe e outros adultos.

Além disso, deve-se apontar a importância dos jogos e dos brinquedos na construção para a criança, de si e do mundo (Schaffer, 1984 e 1990).

É interessante observar que a criança, desde muito pequena, é capaz de reconhecer as várias pessoas ao seu redor e assim estabelecer relações diferenciadas entre elas. Dessa forma, o distanciamento físico da mãe pode propiciar à criança a aprendizagem de que a separação é um componente natural e necessário para o estabelecimento de novas relações satisfatórias fora do seu ambiente doméstico.

Outro fator interessante a ser considerado é que, com a chegada do primeiro filho, algumas mudanças ocorrem na família e são representadas basicamente pela mudança ocasionada pela passagem da vida em conjunto do casal para a incorporação de novos papéis, como os de mãe e pai. Dessa maneira, evidenciam-se:

1. A necessidade de adaptação do ritmo de vida à presença da criança;

2. A necessidade de aceitar a criança no sistema familiar, definindo qual o seu espaço dentro do sistema emotivo e de relações da família (Binda, 1990; Galimberti, 1990).

Assim, o projeto do centro para crianças e suas famílias prevê não apenas o aspecto assistencialista do cuidado com a criança, mas o da prevenção, apoio e integração educativa para os pequenos e suas famílias, de forma que as últimas possam vivenciar de um modo mais tranqüilo e solidário as agruras existentes no trabalho, envolvendo a criação de seus filhos.

Desse modo, acredita-se que o investir na criança implica também a necessidade de investimentos nos adultos diretamente responsáveis por ela, isto é, pais, educadores etc. Portanto a formação dos operadores dos centros é um dos aspectos que mais tem ocupado e preocupado os especialistas.

De acordo com Cardini (1993; 1995), a formação dos operadores dos novos serviços sócioeducativos para crianças e famílias se faz sobretudo no campo, na cotidianidade do seu trabalho. Assim, é necessário que esse profissional tenha, segundo Catarsi (1993; 1995):

1. Competência de caráter teórico e cultural;

2. Competência técnica ou didática;

3. Competência pedagógica;

4. Competência no estabelecimento de relações tanto no trabalho educativo com as crianças quanto 
no trabalho com outros adultos. Portanto a parte mais consistente da formação, a que conta de fato, é a que ocorre no dia-a-dia, amparada por uma reflexão constante sobre a atuação profissional sob a condução de um psicólogo ou psicopedagogo na qualidade de instrutor, ou seja, formando e supervisionando tais profissionais.

Dentro desse contexto, é desejável que os operadores - através de uma formação pessoal contínua, atenta aos aspectos pessoais e interpessoais - sejam pessoas equilibradas, com facilidade de convivência e conhecedoras de suas próprias ambivalências e conflitos.

Um outro aspecto de fundamental importância na organização do serviço nos Centros é o que diz respeito à metodologia do trabalho empregada. Assim, é desejável que a mesma esteja atrelada às necessidades das crianças e de suas famílias. Um exemplo é o tempo do grupo, o qual se constitui num elemento da organização do projeto de crucial importância. O tempo cotidiano deverá prever/consentir uma adequada integração entre as atividades lúdicas ou livres das crianças, as propostas organizadas diretamente pelos operadores, as situações mais ou menos espontâneas promovidas pelos genitores ou outros adultos. Também o tempo histórico deverá prever momentos de observação e de reflexão, a fim de que a observação-documentação-construção de memória se consolidem como componentes eficazes de uma avaliação constante e de um remodelamento permanente do projeto inicial (Catarsi, 1993 op. cit.).

É interessante observar que os projetos veiculados nos Centros dedicam uma parte do seu tempo e espaço aos adultos comprometidos diretamente com os cuidados das crianças, quer sejam eles genitores, avós, babás, etc. de forma a propiciar experiências de socialização, apoio e integração educativa referentes à tarefa de criação e orientação dos pequenos. Desse modo, são previstas atividades para os adultos envolvendo o simples fazer e saborear um cafezinho em conjunto com os outros, num processo de socialização, até atividades mais elaboradas, como, por exemplo, a organização de um ciclo de palestras com especialistas em educação infantil. Além disso, há a possibilidade da organização de diversos tipos de laboratórios como: artesanato, fotografia, pintura etc, bem como são previstos espaços para que os adultos desenvolvam conjuntamente atividades com suas crianças.

Uma preocupação constante em relação aos novos serviços para a infância, entre eles os Centros para crianças e suas famílias, é a que diz respeito à utilização inteligente da estrutura, ou seja, deve-se garantir uma continuidade vertical ou diacrônica e uma continuidade horizontal ou sincrônica. Assim, entende-se por continuidade vertical ou diacrônica a integração entre os serviços tradicionais (creche e escola materna) com a família e outros grupos do contexto social e, por continuidade horizontal ou sincrônica, o prosseguimento entre um grau de escola e outro (ensino pré-escolar/ensino fundamental). Outrossim, os centros para as crianças e suas famílias, segundo Ghedini (1995), deve garantir à criança o direito de uma eficiente formação precoce e garantir à sua família o direito de ter um local adequado para a educação e os cuidados de seus filhos. Entretanto tais garantias devem estar atreladas a um profundo conhecimento das reais necessidades da família, para que não se corra o risco de fornecer serviços inadequados e, muitas vezes, bastante onerosos. Portanto, de acordo com a referida pesquisadora, é possível utilizar de forma racional e inteligente a mesma estrutura de uma escola ou de uma creche para a realização de um centro, pois deve-se considerar que nem todas as crianças permanecem em período integral na instituição.

\section{A experiência de modena}

Ilustraremos, a seguir, a experiência da cidade de Modena, na região de Emilia-Romagna na Itália, com relação aos centros para crianças e suas famílias. 
A prefeitura de Modena vem, desde o final dos anos 60, oferecendo serviços relativos ao atendimento de crianças com até seis anos em creches (asili nidi) e escolas maternas. Em meados dos anos 80, devido às mudanças sócioculturais (aumento do número de mulheres trabalhadoras com filhos, predomínio da familiar nuclear etc), novos serviços foram sendo criados e atrelados ao então "nidi". Datam desta época as experiências "L'erba del nido" e dos centros de jogos denominados "Bianconiglio", "Cappellaio Matto" e "Lo Stregatto". Em 1994, foi inaugurado o "Spazio Incontro", que é uma nova proposta para o atendimento tanto das crianças quanto de seus genitores.

A experiência "L'erba del nido" trata da utilização da área verde de determinadas creches, no período da primavera-verão (que na Itália vai de abril a setembro, com exceção dos meses de julho e agosto que são os de férias), com o objetivo de fornecer ocasiões de brinquedo e de socialização em local livre, para crianças e para os adultos que as acompanham. Normalmente, são formados dois grupos com até vinte e cinco crianças mais os adultos acompanhantes. No período da manhã, o serviço conta com um educador da própria creche e um recreacionista; à tarde, há apenas o recreacionista.

Os centros "Bianconiglio", "Cappellaio Matto" e "Lo Stregatto", paralelamente aos serviços da creche, oferecem ocasiões para atividades lúdicas e de socialização para crianças de diferentes idades e para os adultos que as acompanham. Funcionam no período da tarde com dois educadores e com dois auxiliares para dois grupos com até dezoito crianças.

O "Spazio Incontro" é um serviço que tem como diretrizes fundamentais o de constituir-se em um local de encontro, troca e construção de relações entre os próprios genitores e entre outros adultos que diretamente estão envolvidos nos cuidados com as crianças e também num local para atividades lúdicas das crianças tanto livres quanto direcionadas pelo operador ou por seus auxiliares ou colaboradores.

Assim, segundo Cardini (1993), o projeto de centro das crianças e de suas famílias pode garantir uma diversidade complexa em uma vida integrada e harmônica, quando:

a) A experiência das crianças é acolhida de tal forma que as etapas de seu desenvolvimento são respeitadas bem como as diferenças culturais (raça, sexo, etc.);

b) Ocorre o oferecimento da máxima oportunidade de interação entre criança e criança, criança e pré-adolescente, criança e adulto etc., enfim estimulando a socialização;

\section{Estratégias familiares e políticas da vida cotidiana - uma primeira avaliação dos serviços prestados pelos centros}

As propostas de trabalho voltadas para a agregação e incentivo de relações entre adultos e crianças vêm sendo amplamente abordadas dentro do contexto da Psicologia.

Há uma considerável produção científica recente nos âmbitos nacional e internacional, tratando da importância das interações desde os primeiros momentos de vida de uma criança, através do olhar da psicanálise (Lacroin e Monmayant, 1997) até recentes pesquisas transculturais (Klein, 1996), comprovando a eficiência de boas mediações entre adultos e crianças, no desenvolvimento do potencial cognitivo das últimas, conforme aponta Feurstein, em seu pioneiro Programa de Enriquecimento Instrumental (1980).

Assim, manter serviços sócio-educativos que identifiquem e resgatem a importância da família, que incentivem a sua competência cotidiana, valorizando e reconhecendo socialmente os 
saberes e a eficiência dos pais, sublinhando os seus pontos de força, a sua capacidade e seus recursos pessoais para enfrentarem situações, pode ser considerada a primeira avaliação positiva dos centros em questão, salienta Catarsi (op. cit.). Por outro lado, conforme lembra Quintavalla (1996), existem nos centros alguns aspectos problemáticos, que necessitam de maiores investimentos, como é o caso da formação para os operadores do serviço, em virtude de suas especificidades anteriormente descritas, vê-se que encontrar tal profissional no mercado de trabalho não é tarefa fácil e, portanto, recursos devem ser destinados para essa profissionalização emergente.

Castagnotto (1996) sugere que, em relação à avaliação dos serviços, a pré-condição necessária é liberar a família da estaticidade de seu arquétipo e contextualizá-la na realidade da vida cotidiana, dando voz a sua experiência de vida social, às dinâmicas e aos conflitos oriundos das suas necessidades, escutando e aprendendo com as estratégias espontâneas que as mulheres, homens, velhos e jovens experimentam na sua vivência familiar.

\section{"Centros para crianças e sua famílias": possibilidade de implantação no contexto brasileiro}

Apesar da ampla divulgação que os estudos sobre educação infantil tiveram em escala internacional e do entusiasmo que suscitou em alguns educadores da Europa e das Américas, apesar da grande ênfase dada ao desenvolvimento e aprendizagem da criança, iniciada através das contribuições de médicos, até os avanços da psicanálise e das psicologias experimental e cognitiva, principalmente no nosso século. Na prática, os progressos da educação pré-escolar foram e continuam sendo lentos. A questão de como educar, criar e assegurar uma plena existência ao ser humano, por meio de um desenvolvimento de suas capacidades e habilidades, permanece sem resposta sob muitos aspectos e é marcada por numerosas incertezas, a exigir uma reflexão constante e esforço árduo de todos os que se ocupam da infância, especialmente os estudiosos e os políticos, cabendo aos últimos o dever de implementarem serviços para que todas as crianças tenham o direito de vivenciarem experiências sociais e estimulantes também do ponto de vista intelectual.

Vários projetos atrelados a políticas de atendimento às crianças pequenas, especialmente na faixa de zero a seis anos foram empreendidos em diversos países.

Neste sentido, o Brasil contou com várias recomendações e pareceres (Vectore, 1989), entretanto, faltaram diretrizes políticas eficazes que considerassem efetivamente o problema do serviço à infância. É bem verdade que tentativas isoladas e bem sucedidas existem, como é o caso do Projeto Axé, desenvolvido na cidade de Salvador - BA, com crianças em situação de risco. Infelizmente, a falta de uma política nacional consistente, ainda nos dias de hoje, vem consolidando o triste quadro de abandono e descaso à criança brasileira.

Assim, considerando o insuficiente oferecimento de serviços à infância brasileira, cuja estimativa em 1989 era a que "cerca de 667 mil crianças até quatro anos estariam freqüentando creche ou pré-escola e que aproximadamente 2,8 milhões de crianças entre quatro e seis anos estariam matriculadas em pré-escolas" (MEC, 1994: 13), ou seja, apenas 15\% de crianças teriam acesso a algum tipo de instituição pré-escolar, tem-se que os atuais serviços sócioeducativos à infância e às famílias em plena expansão nos países europeus talvez possam ser implementados em nosso país, através de seus princípios básicos, ou seja, oferecer um serviço flexível, de tal forma a atender aos horários e necessidades da família e o de se utilizar de modo inteligente estruturas já existentes, uma vez que não são necessárias estruturas especiais para abrigar esse tipo de 
atendimento - há necessidade apenas de racionalizar os horários ociosos em escolas, creches, clubes e, até mesmo, utilizar áreas abertas como parques, praças e play-grounds, o que representa uma grande economia levando-se em conta os sempre escassos recursos destinados à educação da criança pequena.

Entretanto uma palavra de cautela talvez deva ser acrescentada, pois, muitas vezes, o conhecimento de uma realidade tão distante da nossa, que vem buscando através de seus serviços para a infância um adequado atendimento à criança, pode mobilizar raciocínios simplistas, susceptíveis de erros primários, passíveis de ocorrência quando se está em jogo a transposição linear de uma realidade para outra, no caso, a realidade italiana para a realidade brasileira. Há que se considerar, dessa forma, as características culturais de cada sociedade bem como as suas necessidades, adequando todos os aspectos que possam ser aproveitados, no sentido também de podermos organizar serviços sócio-educativos eficientes às nossas crianças e às suas famílias, uma vez que comentar a importância de um adequado desenvolvimento, principalmente durante o período infantil, torna-se desnecessário, à medida que tal tema já foi objeto de inúmeras investigações e é, sem dúvida, o melhor passaporte que podemos propiciar às crianças, às portas do terceiro milênio.

Contudo outro aspecto que deve ser considerado é a necessidade da inclusão de um treinamento em serviço para os futuros profissionais que atuarão diretamente com as crianças e com as suas respectivas famílias, uma vez que todo o trabalho deverá ser realizado por profissionais altamente qualificados e sob supervisão constante de profissionais especializados, no caso, basicamente por psicólogos e pedagogos.

É interessante apontar que os centros para atendimento à criança e à família vem sendo, tanto na Itália quanto em outros países europeus, entre eles a França, a Dinamarca, a Espanha, um foro constante de debates visando a uma melhor adequação dos serviços para a infância, pois atender efetivamente crianças e famílias constitui-se num grandioso desafio. Não obstante, pesquisas e estudos deverão ser realizados a fim de que seja verificada a viabilidade de tal projeto junto à sociedade brasileira, bem como as formas mais eficientes de adequá-los à realidade de nossas crianças.

\section{Referências Bibliográficas}

Almy, M. (1977). La tarea Del edllcator preescolar.Buenos Aires: Marymar.

Andreani Dentici, O (org.) (1991). II Pensiero in erba. Ricerce sullo sviluppo dai 5 ai 7 anni. Milano: Angeli.

Barbini, T. (1993). Politiche sociale e diritto alI , educazione. In: E. Catarsi, servizi educative e sociale per i bambini e le loro famiglie. Bergamo: Juvenilia.

Bateson, G. (1976). Verso una ecologia della mente.Milano: Adelphi.

Becchi, E. \& Bondioli, A. (orgs.) (1988). Psicoanalisi ed educazione della prima infanzie. Bambini, ottobre, 4 (10).

Bertolini, P., Galli, M. c., Palmonari, A. \& Saitta, R. (1988). Le ragioni Del nido. Firenze: La Nuova Itália.

Binda, W. (1990). DalIa diade coniugale alIa triade famigliare. In. E. Scabini. L 'organizzazione famiglia tra crisi e sviluppo. Milano: Angeli.

Bondioli, A., Mantovani, S. (org.) (1987). Manuale critico dell'asilo nido. Milano: Angeli. 
Bondioli, A. (1988). Per una didattica psicoanalitica Del gioco. Bambini, ottobre, 4 (10). . (1989). Il bliffone ed il re. Firenze: La Nuova Itália. . (org. do tema) (1990). In gioco. RllOli, relazioni ed afetti. Bambini, maggio, 6 (5).

Camaioni, L. (org.) (1993). Manuale di psicologia dello sviluppo. Bologna: li Mulino.

Camaioni, L., Bascetta, C., Aureli, T. (1988). L 'osservazione Del bambino nel contexto educativo. Bologna: Il Mulino. . (1985). La prima infanzia. Bologna: li Mulino. . (1980). La prima infanzia. Bologna: li Mulino.

Cardini, R. (1996). Comunicação Pessoal..

Castagnotto, P. (1996). Alcune riflessioni conclusive. Genitorialità e Infanzia tra Famiglie Territorio, Settembre, 2 (9): 53-54.

Catarsi, E. (1996). Comunicação Pessoal. .(org.) (1993). 1 servizi per l'infanzia in Europa. Bergamo: Juvenilia.

Juvenilia. (org.) (1993).1 servizi educativi e sociali per i bambini e le loro famiglie. Bergamo: Cerro. (1993). Leggere e capire neUa scuola deU'infanzia ed elementare. Pisa: Edizione Del $\overline{\text { Nuova Itália. }}$

(org.) (1991). La continuità educative fra l'asilo nido e Ia scuola materna. Firenze: La Nuova Itália. Fortunati, A. (org.) (1989). La programmazione progettazione neU'asilo nido. Firenze: La . (1988). La programmazione nell'asilo nido. Bergamo: Juvenilia.

Cesareo, V., Scurati, C. (org.) (1986). Infanzia e continuilà educativa. Milano: Angeli.

Emiliani, F., Carugati, F. (1985). 11 mondo sociale del bambini. Bologna: li Mulino.

Evans, E. D. (1975). Contemporary injluences in early childhood. 2" ed., NY: Holt, Rinehart and Winston.

Fomasa, W. (1989). Errare humanun est. Perseverare puerorum. Bambini: novembre, 5 (11). .and Barba, P. (1988). Programmazione e caos. Bambini: Marzo, 4 (3).

.Del Campo, R., Vanni, A. (1991). Apprendere ad apprendere. In: Bambini: giugno, 7 (6).

Frabboni, F. (1990). La scuola dell'infanzia. Firenze: La Nuova Itália.

.Minerva, F. P. (orgs.) (1992). La sCllola materna e le sue infanzie. Milano: Ethel Editoriale Giorgio Mondadori.

Friedlander, I. (1981). Early reading development. London: Harper and Row.

Galimberti, C. (1990). li processo di formazione de lia coppia. In: E. Scabini. (1990,4" ed.). L 'organizzazione famiglia tra crisi e sviluppo. Milano: Angeli.

Gay, R. (1988). Il nido: sapere efare. Bergamo: Juvenilia. 
Ghedini, P. O. (1996). Comunicação Pessoal.

(1993). Da una politica Del servizi a una politica per l' infanzia. In. E. Catarsi. I servizi educativi e sociale per i bambini e le loro famiglie. Bergamo: Juvenilia.

Gordon, I. (1972). Early childhood education: Seventy-jirst yearbook ofthe National Society for the Study of Education. Chicago: University of Chicago Press.

Kayle, K. (1989). La vila mentale e sociale Del bambini. Roma: li Pensiero Scientifico.

Klein, P. S. (1996). Early Intervention: Cross-Cultural Experiences wilh a Mediational Approach. New Y ork: Garland.

Lacroix, M. B., Monmayrant, M. (orgs.) (1997). Os Laços do Encantamento. Porto Alegre: Artes Médicas.

Lumbelli, L. (org.) (1988). Incoraggiare a leggere. Intenzione e comportamento verbale degli insegnanti. Firenze: La Nuova Itália.

(1981). Comunicazione non autoritaria. Come rinunziare ai "ruolo" in modo construtivo: sugerimenti rogersiani. Milano: Angeli.

Manini, M., Borghi, B. Q. (1991). Da zero a sei anni. Materiali per un progetto di continuilà educativa. Firenze: La Nuova Itália.

Ministério da Educação e do Desporto (1994). Política nacional de educação infantil. Brasília, MECI SEFI DPEI COEDI.

Musatti, T. (1992). La giornata Del mio bambino. Madri, lavora e cura Del piu piccoli nella vita quotidiana. Bologna: II Mulino.

Petter, G. (1993). Fantasia e razionalità nell 'età evolutiva. Firenze: La Nuova Itália.

Pontecorvo, C. (org.) (1990). Una scuola per i bambini. Firenze: La Nuova Italia.

.Tassinari, G., Camaioni, L. (orgs.) (1990). Continuità educativa dai quattro agli otto anni.

Condizioni, metodi e strumenti di una ricerca sperimentale nella scuola. Firenze: La Nuova Itália.

Quintavalla, E. (1996). Strategie e politiche della vita quotidiana. In: Genitorialita e Infanzia tra Famiglie e Territorio, Settembre, 2 (9): 34-41.

Rubagotti, G. (org.) (1992). Manuale diformazione e aggiornamento per i docenti della scuola materna. Milano: Fabbri.

Schaffer, R. (1984). L 'interazione madre-bambino. Oltre Ia teoria dell'attaccamento. Milano: Angeli.

(1990). Il bambino e i suoi partner. Milano: Angeli.

Stem, D. N. (1987). Il mondo interpersonale Del bambino. Torino: Boringhieri.

Ugazio, V. (org.) (1990). Manuale di psicologia educativa. Prima infanzia. Milano: Angeli.

Vectore, C. (1989). Professores, pais e pré-escola: uma pesquisa exploratória em pré-escolas públicas e particulares. São Paulo, Dissertação de Mestrado, Instituto de Psicologia, Universidade de São Paulo.

. (1992). A escolha da pré-escola: um problema de psicologia do consumidor. São Paulo, Tese de Doutorado. Instituto de Psicologia, Universidade de São Paulo.

Zunino, G. (org.) (1991). Nuovi orientamenti per la scuola materna. Roma: Valare Scuola. 